\title{
Bacterial Cellulose Synthesis by Gluconacetobacter xylinus: Enhancement via Fed-batch Fermentation Strategies in Glycerol Media
}

\author{
Azila Adnan ${ }^{1, *}$, Giridhar Nair², Mark Lay ${ }^{3}$ and Janis Swan ${ }^{3}$ \\ ${ }^{I}$ Faculty of Science and Marine Environment, Universiti Malaysia Terengganu 21030, Kuala Nerus, \\ Terengganu, Malaysia \\ ${ }^{2}$ Department of Biotechnology and Biochemical Engineering, Sree Buddha College of Engineering, \\ Alappuzha 690529, India \\ ${ }^{3}$ School of Engineering, Faculty of Science and Engineering, University of Waikato, \\ Hamilton, New Zealand
}

("Corresponding author's e-mail: azila.adnan@umt.edu.my)

Received: 20 July 2020, Revised: 20 March 2021, Accepted: 20 April 2021

\begin{abstract}
Bacterial cellulose (BC) is an abundant polysaccharide, which is secreted by several genera of bacteria. It has remarkable characteristics, which include high purity, high tensile strength, high biocompatibility and non-toxic. The main feature that differentiates $\mathrm{BC}$ and plant cellulose (PC) is the absence of contaminants such as lignin, hemicellulose and pectin. However, the main drawbacks in producing $\mathrm{BC}$ are low yield and expensive carbon source. Due to that, this study was carried out to enhance $\mathrm{BC}$ volumetric productivity in fed-batch operation mode using glycerol as a carbon source. BC was produced in fill-and-draw and pulse-feed fed-batch cultures of Gluconacetobacter xylinus DSM 46604 in a 3-L bench-top bioreactor. The fed-batch fermentation trials were conducted in agitated and aerobic conditions at $30^{\circ} \mathrm{C}$. For fill-and-draw fed-batch culture, a total of $24.2 \mathrm{~g} / \mathrm{L}$ of BC accumulated in the bioreactor after 9 days, which corresponded to a yield and productivity of $0.2 \mathrm{~g} / \mathrm{g}$ and $2.69 \mathrm{~g} / \mathrm{L} / \mathrm{day}$, respectively. Pulse-feed fed-batch fermentation resulted in a yield and volumetric productivity of $0.38 \mathrm{~g} / \mathrm{g}$ and $2.71 \mathrm{~g} / \mathrm{L} /$ day, respectively. The pulse-feed fed-batch culture proved to be a better fermentation system for utilizing glycerol, which is a low-cost and abundant carbon source.
\end{abstract}

Keywords: Bacterial cellulose, Glycerol, Gluconacetobacter xylinus, Yield, Volumetric productivity

\section{Introduction}

The extracellular BC is produced by cellulose-producing bacteria, which fermented in a culture medium containing various carbon sources and nitrogen sources. This biopolymer, which is often produced as discrete particles has high crystallinity, high mechanical strength and higher purity than plant-derived cellulose [1]. Besides, it does not contain components such as lignin and hemicellulose present in plant-derived cellulose [2]. Due to its unique properties, BC is highly suitable for several important biotechnological and biomedical applications and their applications have been reviewed by Lin et al. [3]. However, relatively high cost of production and lower yields are the main challenges in $\mathrm{BC}$ production [4].

BC can be produced by agitated or static cultivation [5]. As Gluconacetobacter xylinus (reclassified as Komagataeibacter xylinus) is the most efficient BC producer [6,7], this bacterium has been widely utilized in $\mathrm{BC}$ production and research. Dourado and colleagues [8] revised the toxicological and dietetic aspects of $\mathrm{BC}$ in an animal model, which leads to a conclusion that $\mathrm{BC}$ synthesized from this bacterium is safe for applications in food technology. A cytotoxicity study conducted by Volova et al. [9] demonstrated that $\mathrm{BC}$ did not created cytotoxicity with mouse fibroblast cells.

The $\mathrm{BC}$ produced in agitated cultures is initially extruded from the cell surface as microfibers and entangles to form ribbons, which then intertwine to form a dense, gelatinous pellicle at the air/liquid interface [10]. It is difficult to gain a high productivity in large scale cultures due to its low yield under agitated cultivations. Hence, several strategies have been attempted by many researchers such as the optimal medium, the culture conditions and their interaction effects [11] to improve BC production. 
One of the ways of reducing the cost of $\mathrm{BC}$ production is by using low-cost raw materials in fermentations. Glycerol is one such raw material, which can be used as carbon source in the fermentative production of BC. In recent years, glycerol is produced in abundance as a result of the expanding biodiesel industry. Approximately $10 \%(\mathrm{w} / \mathrm{w})$ of glycerol is obtained from biodiesel production [12] and it is estimated that the production of glycerol will reach 5.8 billion pounds (2.6 million tons) in 2020 [13]. The glycerol generated from biodiesel industry contains several impurities that make its disposal costly and difficult [14]. As a result, the price of glycerol is forecasted to fall in the coming years, making it an ideal raw material for industrial processes [15].

In order to obtain high $\mathrm{BC}$ concentration and productivity, it is highly desired to process high concentrations of glycerol under non-inhibitory levels with maximum utilization of reactor volume. Fedbatch cultures are extensively attempted to process very high substrate concentrations without inhibiting bacterial growth. Typically, in a fed-batch culture, the substrate concentration in the feed is very high to minimize the dilution of culture. The feeding is preceded by a batch phase and by using several predetermined feeding strategies, the batch phase is switched to fixed volume fed-batch or variable volume fed-batch cultures. The fill-and-draw culture, also known as repeated fed-batch or cyclic fed-batch culture, is a fixed volume fed-batch process in which a portion of the culture is periodically withdrawn and the biomass remaining in the bioreactor is diluted to the original volume with fresh medium containing the substrate. For pulse-feed fed-batch, pulses are introduced to supply substrate before it is completely depleted [16]. Batch fermentation strategy is the simplest process; however, it suffers from low cell biomass and low product productivity due to depleted nutrients, substrate inhibition, and prolonged fermentation time [17]. Thus, fed batch fermentation strategy might overcome substrate inhibition and results in high product concentration [18].

In this proposed study, the fill-and-draw and pulse-feed fed-batch culture strategy was conducted to enhance the yield and productivity of BC.

\section{Materials and methods}

\section{Microorganism and media}

Gluconacetobacter xylinus DSM 46604, purchased from the German collection of microorganisms and cell cultures (DSMZ), was used in this study. Stock cultures of the bacterium were grown at $30{ }^{\circ} \mathrm{C}$ on nutrient agar slants having the following composition $(\mathrm{g} / \mathrm{L})$ : D-glucose, 50; yeast extract, 5; ammonium sulphate, 5; disodium hydrogen phosphate, 3; magnesium sulphate 0.05; agar, 20. The growth and seed media used were of the same composition (without agar). All chemicals used were of analytical grade. Distilled water was used to prepare all solutions. Seed culture was prepared by aseptically transferring a loop full of cells from the stock culture into $75 \mathrm{~mL}$ of seed medium in a $200-\mathrm{mL}$ conical flask. The cultures were incubated at $30{ }^{\circ} \mathrm{C}$ and $150 \mathrm{rpm}$ for 5 days until white pellicles were appeared.

\section{Shake flask cultures}

For shake flask studies, the seed culture was aseptically transferred into $65 \mathrm{~mL}$ medium in $200-\mathrm{mL}$ shake flasks containing (g/L): glucose, 20; yeast extract, 5, ammonium sulphate, 5; potassium hydrogen orthophosphate, 3; magnesium sulphate, 0.05 . The $\mathrm{pH}$ of the medium was adjusted to 6.8 with $6 \mathrm{M}$ $\mathrm{NaOH}$. The cultures were incubated at $30{ }^{\circ} \mathrm{C}$ and $150 \mathrm{rpm}$ for 5 days. Large-scale cultures using glycerol as a carbon source were grown in a 3-L bench-top bioreactor (BioFlo, Celligen 115) with a working volume of $2 \mathrm{~L}$. The medium was composed of $(\mathrm{g} / \mathrm{L})$ : glycerol, 20; yeast extract, 5; ammonium sulphate, 5; potassium hydrogen orthophosphate, 3; magnesium sulphate, 0.05 . The $\mathrm{pH}$ of the culture broth was controlled at 6.8 by automatic addition of $1 \mathrm{M} \mathrm{NaOH}$. The bioreactor was inoculated with $150 \mathrm{~mL}$ of seed culture and grown at $30^{\circ} \mathrm{C}$ and $0.3 \mathrm{vvm}$ aeration for 5 days. Culture samples were withdrawn from the bioreactor every $24 \mathrm{~h}$ for glycerol, biomass and BC determination. During fermentation, antifoam was added intermittently in order to prevent foaming in the bioreactor. The result is shown in Figure 1.

\section{Fill-and-draw fed-batch culture}

Fill-and-draw fed-batch cultures were initiated as batch cultures using the medium containing 20 $\mathrm{g} / \mathrm{L}$ glycerol in a 3-L bench-top bioreactor (BioFlo, Celligen 115) with a working volume of 2 L. After 3 days of cultivation, the batch culture was switched to fill- and-draw fed-batch culture by withdrawing $1 \mathrm{~L}$ of culture broth from the bioreactor and adding $1 \mathrm{~L}$ of fresh medium containing double strength culture media along with other nutrients to give $2 \mathrm{~L}$ final volume. The concentrations of yeast extract, ammonium sulphate, potassium hydrogen orthophosphate, and magnesium sulphate were also doubled 
proportionately in the feed, so that they are non- limiting. After the $3^{\text {rd }}$ cycle, the fermentation was continued as a batch until most of the glycerol added has been consumed.

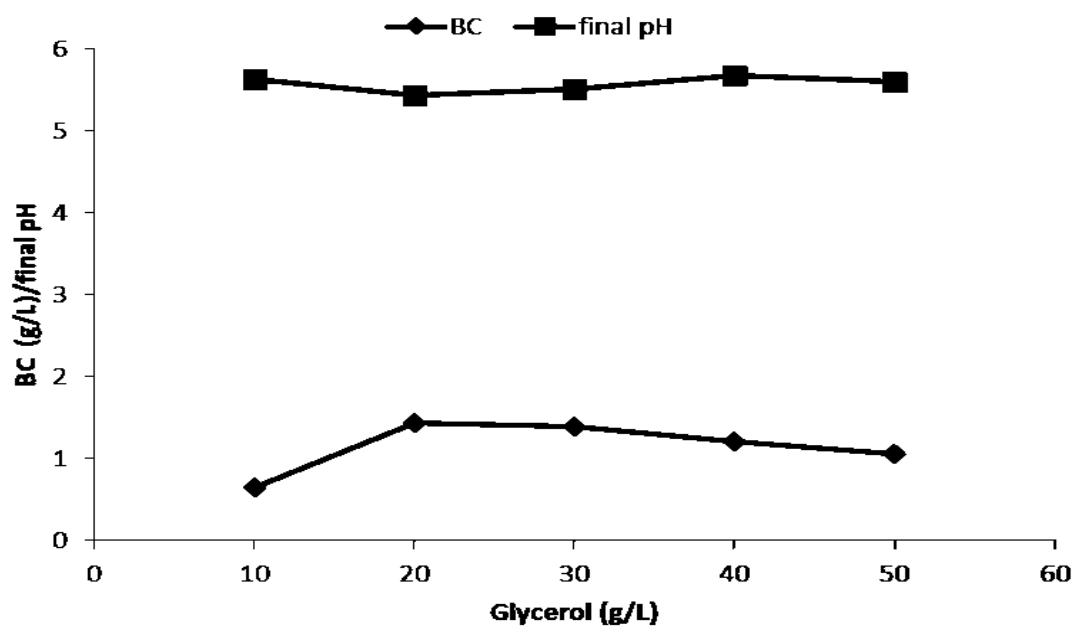

Figure 1 Effect of initial glycerol concentration on BC production (g/L) by G. xylinus DSM 46604.

\section{Pulse-feed culture}

For pulse feed fed-batch culture, this involved feeding $3250-\mathrm{mL}$ lots of double strength culture media on days 3,5 and 7. Fermentation continued until day 9. Biomass, glycerol and BC concentrations in culture broth samples taken immediately before and after adding new media were determined. The initial volume of working was $1 \mathrm{~L}$, followed by adding 3 lots of $250-\mathrm{mL}$ double strength media to give a final volume of $1750 \mathrm{~L}$.

\section{Sample preparation}

The samples taken from shake flasks or bioreactor were split into a sample for cellulose determination and one for biomass determination. Each sample was centrifuged at $4000 \mathrm{rpm}$ for $20 \mathrm{~min}$ to remove the pellets. The supernatant was kept for glycerol analysis. The pellets were washed with distilled water and centrifuged again. The washing procedure was repeated thrice, and the washed pellets were used to determine biomass and $\mathrm{BC}$ concentration.

\section{Bacterial cellulose determination}

The washed pellet was treated with $1 \mathrm{M} \mathrm{NaOH}$ at $90{ }^{\circ} \mathrm{C}$ for $30 \mathrm{~min}$ to dissolve the cells. The solution was centrifuged at $4000 \mathrm{rpm}$ for $20 \mathrm{~min}$, washed with distilled water, centrifuged, and dried at 80 ${ }^{\circ} \mathrm{C}$ for $24 \mathrm{~h}$, and weighed. The yield of cellulose was calculated as total $\mathrm{BC}$ produced divided by the total glycerol utilized and is expressed as $\mathrm{g} \mathrm{BC/g}$ glycerol. The volumetric productivity was calculated as the total cellulose produced in $\mathrm{g} / \mathrm{L}$ divided by the final volume $\times$ culture time and is expressed as $\mathrm{g} / \mathrm{L} / \mathrm{day}$.

\section{Biomass}

The pellets from the samples for biomass determination were suspended in $10 \mathrm{~mL}$ cellulase enzyme (SIGMA) and $90 \mathrm{~mL}$ citrate buffer (pH 5.0), mixed for $5 \mathrm{~min}$, then centrifuged at $4000 \mathrm{rpm}$ for $20 \mathrm{~min}$ to remove the suspended solids. The supernatant was kept at $50^{\circ} \mathrm{C}$ for $30 \mathrm{~min}$ to hydrolyze the $\mathrm{BC}$. The sample was then washed, centrifuged at $4000 \mathrm{rpm}$ for $20 \mathrm{~min}$ and dried at $80^{\circ} \mathrm{C}$ for $24 \mathrm{~h}$, and weighed until constant weight was achieved. The biomass concentration was expressed as gram dry cell weight per liter.

\section{Residual glycerol}

The glycerol concentration was determined by the refractometric method [19]. 


\section{Results and discussion}

\section{Shake flask culture}

Shake flask cultures were carried out to study the effect of glycerol concentration on the final $\mathrm{pH}$ and production of BC on different glycerol concentrations by Gluconacetobacter xylinus and the result is shown in Figure 1. The initial concentration of glycerol in the growth medium was varied between 10 and $50 \mathrm{~g} / \mathrm{L}$.

The $\mathrm{BC}$ production increased when the concentration of glycerol was increased from $10 \mathrm{~g} / \mathrm{L}$ to 20 $\mathrm{g} / \mathrm{L}$. The highest $\mathrm{BC}$ production was $1.43 \mathrm{~g} / \mathrm{L}$ on $20 \mathrm{~g} / \mathrm{L}$ glycerol. Further increase in the concentration of glycerol resulted in decreased $\mathrm{BC}$ production. When conducting a microbial process (e.g fermentation), it prone to generate various environmental stressors that may resulting negative effect on the bacterial growth and culture metabolism. High concentrations of glycerol influence an inhibitory effect on growth of Gluconacetobacter sp. [20]. As reported by Syzmanowska-Powalowska [21], one of the factors that may cause this condition is high substrate/carbon source concentration, which may cause an obvious influence on the osmotic potential of a fermentation broth, which may limit the secretion of BC by the bacteria. When substrate concentration is low, the phase of adaptation is shorter, and the elimination of the substrate is easy.

Furthermore, the fermentation may become viscous, which then may decline the BC production. The increase of broth viscosity may cause by the accumulation of biomass/cell mass, which limits the oxygen transfer from the liquid phase to cells becomes complex [22]. Though agitation speed gives a direct influence on mixing mechanism that could reduce viscosity and increase oxygen solubility and transfer in broth, shear forces caused by the reactor impeller will give a negative effect on cell growth and metabolite accumulation [23]. Additionally, Figure 1 also depicts that $20 \mathrm{~g} / \mathrm{L}$ displayed the lowest final $\mathrm{pH}$, which is approximately 5.5, compared to other concentrations. This condition happens as several factors are occurring at the same time during fermentation process; dissolved oxygen decreased, which could be due to aerobic metabolism by the bacterial cell, removing carbon dioxide and involving the formation of certain intermediates that might influence the $\mathrm{pH}$ condition in the fermentation broth [24].

\section{Fill-and-draw fed-batch culture}

The fill-and-draw culture was initiated as a batch culture with a medium containing $20 \mathrm{~g} / \mathrm{L}$ glycerol since the culture did not exhibit any substrate inhibition at this concentration (Figure 2(A)). When the concentration of glycerol fell to approximately $5 \mathrm{~g} / \mathrm{L}$ (after 3 days), $1 \mathrm{~L}$ of culture broth was removed from the bioreactor and the total volume of culture was maintained by instantaneously replenishing the volume removed with fresh medium containing doubled concentration of carbon source; $40 \mathrm{~g} / \mathrm{L}$ glycerol to prevent carbon source depletion. Thus, the effect of glycerol maintenance concentration on BC production was first investigated in fill-and-draw fed-batch cultivation of G. xylinus (Figure 2(A)).
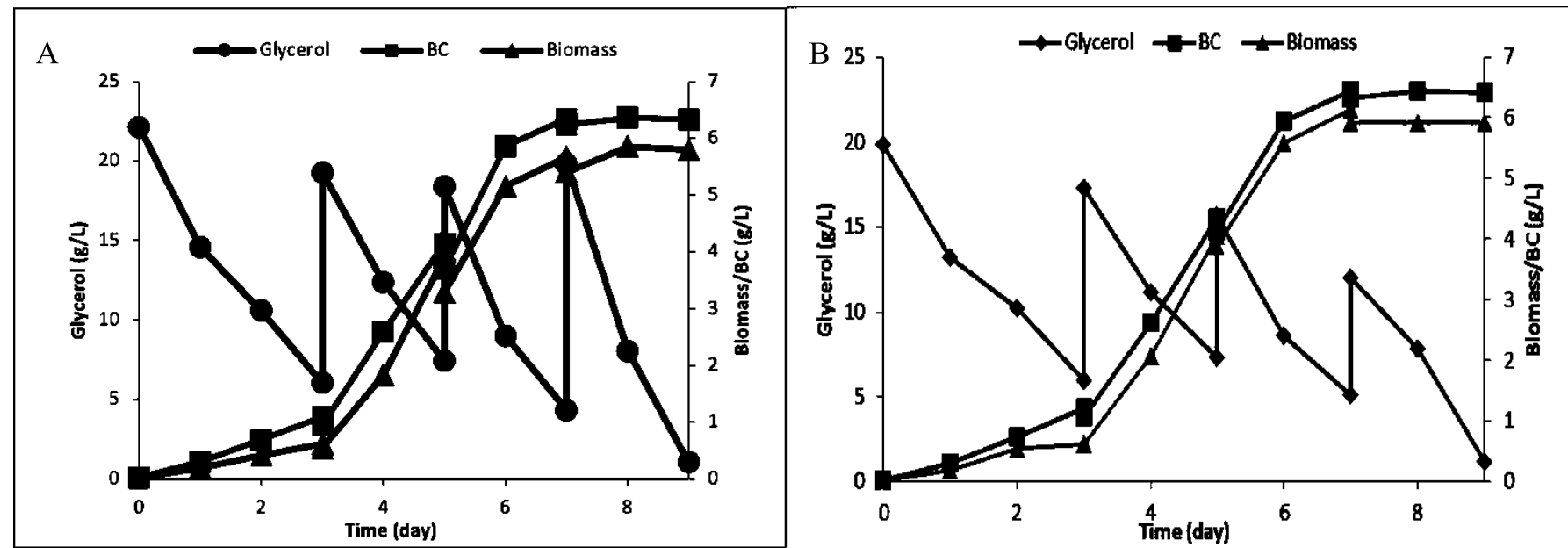

Figure 2 Glycerol, biomass and BC profiles when growing G. xylinus DSM 46604 under a fill-and-draw strategy (A) and Glycerol, biomass and BC profiles when growing G. xylinus DSM 46604 under a fedbatch pulse feed strategy $(B)$. 


\section{Pulse-feed fed-batch culture}

The fermentation was initiated in batch mode with $20 \mathrm{~g} / \mathrm{L}$ glycerol and then switched to pulse feed. Fresh media $(250 \mathrm{~mL}$ at each pulse) was added when glycerol concentration in the fermenter had decreased to about $5 \mathrm{~g} / \mathrm{L}$. Biomass concentration at the end of fermentation was $5.9 \mathrm{~g} / \mathrm{L}$, (Figure 2(B)), which was higher than for fill-and-draw culture. Maximum BC concentration under pulse feed fed-batch culture was $6.4 \mathrm{~g} / \mathrm{L}$, which was similar using fill-and-draw fed-batch culture (Figure 2(A)). However, pulse-feed operation improved BC yield, which was $0.38 \mathrm{~g} / \mathrm{g}$ compared to $0.2 \mathrm{~g} / \mathrm{g}$ for fill-and-draw. Almost all the added glycerol was consumed under both fill-and-draw (Figure 2(A)) and pulse-feed (Figure 2(B)) fermentation mode.

The BC productivity in pulse feed fed-batch mode was $2.71 \mathrm{~g} / \mathrm{L} /$ day and the $\mathrm{BC}$ yield was $0.38 \mathrm{~g}$ per $g$ glycerol used. This was higher than the values obtained in fill-and-draw culture, which produced a $\mathrm{BC}$ yield of $0.2 \mathrm{~g} / \mathrm{g}$ and a $\mathrm{BC}$ productivity of $2.69 \mathrm{~g} / \mathrm{L} /$ day. The data demonstrated that using glycerol as the carbon source enhanced 1-fold BC productivity and almost doubled BC yield. Overall BC yield and $\mathrm{BC}$ volumetric productivity were displayed in Table 1 for both operation modes.

Table 1 Glycerol consumption, BC yield and productivity in fill-and-draw and pulse feed fed-batch using glycerol as the carbon source.

\begin{tabular}{lcc}
\hline \multirow{2}{*}{ Parameters } & \multicolumn{2}{c}{ Mode of Operation } \\
\cline { 2 - 3 } & Fill-and-Draw Fed Batch & Pulse-Feed Fed Batch \\
\hline Duration (days) & 9 & 9 \\
Maximum BC concentration (g/L) & 6.4 & 6.4 \\
Total glycerol consumed (g/L) & 121.5 & 63.38 \\
Total BC formed (g/L) & 24.2 & 24.38 \\
BC yield (g/g) & 0.2 & 0.38 \\
BC productivity (g/L/day) & 2.69 & 2.71 \\
\hline
\end{tabular}

The data revealed that using glycerol as the carbon source enhanced 1-fold BC productivity and almost doubled $\mathrm{BC}$ yield. The result promises the utilization of by-product glycerol from biodiesel industry on a large-scale, which otherwise would be an environmental burden. For fed-batch operation mode, the selections of ideal feeding time, feeding rate, and concentration of feeding medium are crucial for obtaining optimal cell growth and BC productivity [25]. Most of the fed-batch fermentations have been attempted to reduce the deleterious effects of substrate and/or the inhibitor of production and to reduce the processing costs, which related to the inoculation preparation procedure. Many reactor conditions during batch fermentation will generate a decrease in the specific rate of cell growth, and inhibition can be caused by either the substrate or the end-product. Other fermentation modes have been performed to overcome product and substrate inhibition and to improve the product tolerance of reactor environmental factors. Among them, the choice of an appropriate process mode and process optimization, such as fed-batch, continuous or semi-continuous [26], and/or manipulation of the composition of cultural media [27], has been one of the most widely discovered operation modes. The fed-batch culture with the intermittent feeding of substrate and without harvesting of the fermentation media, is one of the most common strategies used to produce product in the industry. The benefits of this process mode include the reduction of substrate and end-product inhibition, higher dissolved oxygen rate, better saccharification rate, reduced fermentation time, and higher productivity of fermentation product.

\section{Conclusions}

After high productivity conditions have been established, the physical properties and therefore potential uses of the $\mathrm{BC}$ can be determined. The next phase would then be obtaining accurate data for scale up process and estimating production costs. The bottlenecks in processing high concentrations of glycerol to enhance the yield and productivity of BC are growth inhibition and decreased oxygen solubility at high concentrations of glycerol in the culture broth. The higher BC yield and productivity obtained in this study demonstrated that the fill-and-draw fed-batch culture is a suitable method by which 
high concentration of glycerol can be processed without affecting culture growth and oxygen solubility. The fill-and-draw fed-batch cultivation produced $24.2 \mathrm{~g} / \mathrm{L}$ of total $\mathrm{BC}$ corresponding to a yield and productivity of $0.2 \mathrm{~g} / \mathrm{g}$ and pulse feed fed-batch produced $24.38 \mathrm{~g} / \mathrm{L}$ of total $\mathrm{BC}$, which corresponds to a yield of $0.38 \mathrm{~g} / \mathrm{g}$. This demonstrated that pulse-feed fed-batch culture favored in enhancing BC yield and also productivity (g/L/day). In addition, we propose that the fed-batch fermentation in glycerol medium at low sugar concentration represents a favorable influence in improving BC yield. The study suggested that fed-batch cultivation showed potential option for industrial production of BC using G. xylinus, which could also be useful for cultivation of other microorganisms to improve yield and reduce production cost. Additionally, the mechanisms study at metabolite level is recommended to further optimize production processes solely for G. xylinus.

\section{Acknowledgements}

The authors acknowledged the scholarships from Ministry of Higher Education, Malaysia and Universiti Malaysia Terengganu for carrying out this research at The University of Waikato.

\section{References}

[1] M Shoda and Y Sugano. Recent advances in bacterial cellulose production. Biotechnol. Bioprocess Eng. 2005; 10, 1 .

[2] BV Mohite and SV Patil. A novel biomaterial: Bacterial cellulose and its new era applications. Biotechnol. Appl. Biochem. 2014; 61, 101-10.

[3] SP Lin, IL Calvar, JM Catchmark, JR Liu, A Demirci and KC Cheng. Biosynthesis, production and applications of bacterial cellulose. Cellulose 2013; 20, 2191- 219.

[4] F Esa, SM Tasirin and NA Rahman. Overview of bacterial cellulose production and application. Agric. Agric. Sci. Procedia 2014; 2, 113-9.

[5] A Krystynowicz, W Czaja, A Wiktorowska-Jezierska, M Goncalves-Miskiewicz, M Turkiewicz and S Bielecki. Factors affecting the yield and properties of bacterial cellulose. J. Microbiol. Biotechnol. 2002; 29, 189-95.

[6] H El-Saied AH Basta and RH Gobran. Research progress in friendly environmental technology for the production of cellulose products (Bacterial cellulose and its application). Polym. Plast. Technol. Eng. 2004; 43, 797-820.

[7] Y Yamada, P Yukphan, HTL Vu, Y Muramatsu, D Ochaikul and Y Nakagawa. Subdivision of the genus Gluconacetobacter Yamada, Hoshino and Ishikawa 1998: The proposal of Komagatabacter gen. nov., for strains accommodated to the Gluconacetobacter xylinus group in the $\alpha$-Proteobacteria. Ann. Microbiol. 2012; 62, 849-59.

[8] F Dourado, M Gama and AC Rodrigues. A review on the toxicology and dietetic role of bacterial cellulose. Toxicol. Rep. 2017; 4, 543-53.

[9] TG Volova, SV Prudnikova, AG Sukovatyi and EI Shishatskaya. Production and properties of bacterial cellulose by the strain Komagataeibacter xylinus B-12068. Appl. Microbiol. Biotechnol. 2018; 102, 7417-28.

[10] KC Cheng, JM Catchmark and A Demirci. Enhanced production of bacterial cellulose by using a biofilm reactor and its material property analysis. J. Biol. Eng. 2009; 3, 12.

[11] F Mohammadkazemi, M Azin and A Ashori. Production of bacterial cellulose using different carbon sources and culture media. Carbohydr. Polym. 2015; 117, 518-23.

[12] DT Johnson and KA Taconi. The glycerine glut: Options for the value-added conversion of crude glycerol resulting from biodiesel production. Environ. Prog. 2007; 26, 338-48.

[13] $M$ Ayoub and AZ Abdullah. Critical review on the current scenario and significance of crude glycerol resulting from biodiesel industry towards more sustainable renewable energy industry. Renew. Sust. Energ. Rev. 2012; 16, 2671-86.

[14] DT Johnson and KA Taconi. The glycerine glut: Options for the value-added conversion of crude glycerol resulting from biodiesel production. Environ. Prog. 2007; 26, 338-48.

[15] GPD Silva, M Mack and J Contiero. Glycerol: A promising and abundant carbon source for industrial microbiology. Biotechnol. Adv. 2009; 27, 30-9.

[16] S Yzturk, P Yalik and TH Yzdamar. Fed-batch biomolecule production by Bacillus subtilis: A state of the art review. Trends Biotechnol. 2016; 34, 329-45.

[17] MA Abdel-Rahman, Y Tashiro and K Sonomoto. Recent advances in lactic acid production by microbial fermentation processes. Biotechnol. Adv. 2013; 31, 877-902. 
[18] J Tan, MA Abdel-Rahman and K Sonomoto. Biorefinery-based lactic acid fermentation: Microbial production of pure monomer product. In: MD Lorenzo and R Androsch (Eds.). Synthesis, structure and properties of poly (lactic acid). Adv. Polym. Sci. 2018; 279, 27-66.

[19] L Stasiak-Rozanska, S Blazejak and A Miklaszewska. Application of immobilized cell preparation obtained from biomass of Gluconacetobacter xylinus bacteria in biotransformation of glycerol to dihydroxyacetone. Acta Sci. Pol. Technol. Aliment. 2011; 10,35-49.

[20] L Ma, W Lu, Z Xia and J Wen. Enhancement of dihydroxyacetone production by a mutant of Gluconobacter oxydans. Biochem. Eng. J. 2010; 49, 61-7.

[21] D Syzmanowska-Powalowska. The effect of high concentrations of glycerol on the growth, metabolism and adaptation capacity of Clostridium butyricum DSP1. Electron. J. Biotechnol. 2015; 18, 128-33.

[22] Y Zhou, LR Han, HW He, B Sang, DL Yu, JT Feng and X Zhang. Effects of agitation, aeration and temperature on production of a novel glycoprotein GP-1 by Streptomyces kanasenisi ZX01 and scale-up based on volumetric oxygen transfer coefficient. Molecules 2018; 23, 125.

[23] AL Kamble, VS Meena and UC Banerjee. Effect of agitation and aeration on the production of nitrile hydratase by Rhodococcus erythropolis MTCC 1526 in a stirred tank reactor. Lett. Appl. Microbiol. 2010; 51, 413-20.

[24] B Lekhif, A Kerbeche, G Hebrard, N Dietrich J Echaabi. Influence of initial glycerol concentration upon bacterial cells adaptability and biodegradation kinetics on a submerged aerated fixed bed reactor using BiocellA® (PE05) packing. Afr. J. Environ. Sci. Technol. 2015; 9, 71-9.

[25] M Nocentini, D Fajner, G Pasquali and F Magell. Gas-liquid mass transfer and holdup in vessels stirred with multiple rushton turbines: Water and water-glycerol solutions. Ind. Eng. Chem. Res. 1993; 32, 19-26.

[26] S Bae and M Shoda. Bacterial cellulose production by fed-batch fermentation in molasses medium. Biotechnol. Prog. 2004; 20, 1366-71.

[27] B Caylak and SV Sukan. Comparison of different production processes for bioethanol. Turk. J. Chem. 1998; 22, 351-9.

[28] S Alfenore, C Molina-Jouve, SE Guillouet, JL Uribelarrea, G Goma and L Benbadis. Improving ethanol production and viability of Saccharomyces cerevisiae by vitamin feeding strategy during fed batch process. Appl. Microbiol. Biotechnol. 2002; 60, 67-72. 